\title{
MARCADORES MOLECULARES ASOCIADOS CON RESISTENCIA A LA ENFERMEDAD PUNTA MORADA EN PAPA ${ }^{1}$
}

\author{
Fermín Orona-Castro ${ }^{2}$, Víctor Pecina-Quintero ${ }^{3}$, Mateo Armando Cadena-Hinojosa ${ }^{4}$, \\ Mario Alberto Rocha-Peña ${ }^{5}$, Fulgencio Martín Tucuch-Cauich ${ }^{2}$, Isidro Humberto Almeyda-León ${ }^{5}$
}

\section{RESUMEN}

Marcadores moleculares asociados con resistencia a la enfermedad punta morada en papa. El objetivo de este trabajo fue identificar marcadores DNA Polimórfico Amplificado al Azar (RAPDs) y Secuencias Simples Repetidas (SSRs) también conocidos como Microsatélites asociados con la resistencia al daño causado por fitoplasmas en papa. Se evaluó la severidad de la punta morada de la papa (PMP) y la aparición de color pardo en el tubérculo, así como también se realizaron análisis moleculares en variedades y líneas avanzadas de papa. El estudio se realizó en el laboratorio de biotecnología de la Facultad de Ciencias Biológicas de la Universidad Autónoma de Nuevo León - Instituto Nacional de Investigaciones Forestales Agrícolas y Pecuarias (INIFAP), México en el 2003 y 2004. Las técnicas utilizadas fueron RAPDs y SSRs también conocido microsatélites. Tres genotipos mostraron resistencia a la aparición del color pardo del tubérculo, mientras que del análisis molecular seis materiales formaron un grupo que incluyó los genotipos con valores de daño mínimos (entre uno y tres de la escala). Los genotipos restantes formaron dos grupos con presencia de color pardo en el tubérculo mayor (entre cinco y siete). Se identificaron marcadores moleculares posiblemente asociados con tolerancia a la coloración parda del tubérculo. En el análisis de componentes principales y el dendograma generado los materiales que presentaron menor severidad de daño, quedaron incluidos en un mismo grupo, mientras que materiales con mayor severidad de daño quedaron en un grupo diferente.

Palabras claves: PCR, RAPD, SSR, genotipos, fitoplasmas.

\begin{abstract}
Molecular markers associated with resistance to the potato purple-tip disease. The objective was to identify random polymorphic amplified DNA (RAPDs) and simple sequences repeats (SSRs), also known as micro-satellite markers, associated with resistance to fitotoplasm-caused diseases in potato. The severity of the potato purple-tip (PTP) and browning of the tubers were evaluated and molecular analyses of commercial varieties and advanced lines were also performed. The study was conducted at the Laboratory of Biotechnology of the Biological Sciences Faculty of the Universidad Autónoma de Nuevo León - Instituto Nacional de Investigaciones Forestales Agrícolas y Pecuarias (INIFAP), México, in years 2003 and 2004. We utilized RAPD techniques and SSR. Three genotypes showed tolerance to browning, while the molecular analysis grouped six materials that included the genotypes with lowest damage (1-3 of the disease scale). The remaining genotypes made two groups with browning of the main tuber (5-7). Molecular markers possibly associated with tolerance to potato tuber browning were identified. Main component analysis and the dendograms generated permitted the inclusion of genotypes with reduced damage in a single group, while that the materials with highest damage mad a separate category.
\end{abstract}

Key words: PCR, RAPD, SSR, genotypes, fitotoplasms.

1 Recibido: 8 de febrero, 2008. Aceptado: 20 de marzo, 2009. Parte de la tesis de doctorado del primer autor.

2 Campo Experimental Edzná. Instituto Nacional de Investigaciones Forestales Agrícolas y Pecuarias. Campeche, México. fermin. oronacastro@gmail.com, tucuch.fulgencio@inifap.gob.mx

3 Campo Experimental Río Bravo. Instituto Nacional de Investigaciones Forestales Agrícolas y Pecuarias. Tamaulipas, México. pecina.victor@ inifap.gob.mx

4 Campo Experimental Valle de México. Instituto Nacional de Investigaciones Forestales Agrícolas y Pecuarias. Toluca, México. cadena. mateo@inifap.gob.mx

5 Campo Experimental General Terán. Instituto Nacional de Investigaciones Forestales Agrícolas y Pecuarias/Universidad Autónoma de Nuevo León, Unidad de Investigación en Biología Celular y Molecular. Nuevo León, México. rocha.mario@inifap.gob.mx, almeyda.isidro@ inifap.gob.mx 


\section{INTRODUCCIÓN}

La punta morada de la papa (PMP) es una enfermedad ocasionada por fitoplasmas que causa daños de significancia económica en el mundo. En México, es una de las principales limitantes de la producción en las áreas con cultivo comercial de papa. A la fecha, no se han identificado marcadores moleculares relacionados con la resistencia a la enfermedad en los programas de mejoramiento genético.

Doi et al. (1967) demostraron la presencia de organismos tipo micoplasmas en el floema de plantas infectadas con escoba de bruja de la papa. Anteriormente, se consideraba que las enfermedades ocasionadas por fitoplasmas eran causadas por virus. En la actualidad, se han reportado varias enfermedades del cultivo de papa, producidas por fitoplasmas, como es el caso del enrollamiento púrpura del ápice, flavescencia marginal, escoba de bruja, filodia de la papa y marchites de la punta morada (Salazar 1998). Almeyda et al. (1999) encontraron que en plantas enfermas con punta morada se originan brotes erectos y las hojas se enrollan hacia arriba con el progreso de la enfermedad. Además, se produce una pigmentación de color púrpura en la base de los foliolos mientras que los tallos se marchitan debido a la necrosis del floema. Las plantas jóvenes afectadas pueden producir tubérculos aéreos así como un engrosamiento de los nudos del tallo. Los tubérculos producidos por las plantas infectadas pueden ser flácidos y producir brotes ahilados cuando se rompe la dormancia así como una ausencia de brotación en los mismos.

En México, el tizón tardío y la enfermedad PMP son consideradas como las más importantes del cultivo de la papa. El nombre de PMP se debe a la coloración morada que adquieren las hojas apicales. Por otra parte, se pueden desarrollar tubérculos aéreos en los nudos de los tallos.

Los síntomas de la enfermedad se detectaron en México desde hace 50 años; sin embargo, su importancia se ha incrementado en los últimos cinco años (Almeyda et al. 1999). En la actualidad, se estima que en México más del $50 \%$ de la superficie sembrada con papa es afectada por la enfermedad. Las pérdidas varían según la severidad del problema, pudiendo llegar a reducir el rendimiento hasta en un $80 \%$. Además de esta reducción, los tubérculos infectados pierden valor en el mercado por la necrosis interna y la baja calidad industrial (Salazar 1998).
Por otra parte, se han presentado evidencias de la asociación de fitoplasmas con la PMP (Cárdenas et al. 1992, Almeyda et al. 1999, Martínez et al. 1999). Almeyda et al. (1999) encontraron que es posible la detección de fitoplasmas asociados con la PMP en etapas tempranas de la enfermedad aún en plantas asintomáticas. Otros investigadores han determinado que, por lo menos, existen dos grupos de fitoplasmas asociados con la PMP en México (Almeyda et al. 1999, Martínez et al. 1999, Leyva y Martínez-Soriano 2002).

Recientemente, los esfuerzos en la investigación fueron enfocados a la caracterización molecular del germoplasma, la identificación de nuevas razas de fitoplasmas y al establecimiento de las relaciones genéticas entre colectas con el fin de hacer un uso y conservación mas adecuado e identificar marcadores moleculares asociados con la respuesta al daño causado por estos patógenos (Villalobos et al. 2002, Borth et al. 2002, Lee et al. 1998, Laviña y Battle 2002). A pesar del desarrollo de tecnologías basadas en el DNA, que permitieron contar con un mayor número de marcadores como los RFLPs y los basados en PCR como son RAPD, SSR, AFLP (Milbourne et al. 1997) en México no se han realizado estudios utilizando estas técnicas, pero se debe de considerar que los marcadores RAPDs tienen como desventaja no ser reproducibles entre laboratorios (Demeke et al. 1993), aunque Pecina et al. (2001) demostraron la factibilidad de su reprodubilidad. Kochieva (2000) utilizó varios iniciadores microsatélites y observó que todas las bandas amplificadas en solanáceas estuvieron ausentes en los perfiles de otras especies evaluadas. Este autor concluyó que esas bandas eran marcadores específicos de solanáceas.

Una de las razones principales para el desarrollo de marcadores moleculares, es su potencial uso como marcador diagnóstico para tratamientos importantes en programas de mejoramiento de plantas. El primer ejemplo de un microsatélite ligado a un gene de resistencia a enfermedades de las plantas fue publicado por Yu et al. (1994). Una repetición (A-T) ${ }_{15}$ se localizó dentro del gene de shok térmico de la proteína de soya a una distancia de 0,5 centimorgan del gen Rsv, que es quien confiere resistencia al virus mosaico de la soya.

Los genes de resistencia al virus moteado del cacahuate (Rpv), y de Phytophthora (Rps 3), están agrupados en el grupo de ligamiento $\mathrm{E}$ del genoma de la soya. A pesar de que se ha realizado suficiente 
investigación en el tema, los programas de mejoramiento genético de papa en México adolecen de esta tecnología, el objetivo fue identificar marcadores moleculares asociados a resistencia al daño de fitoplasmas en papa con las técnicas RAPD y SSR. Los resultados permitirán a los fitomejoradores apoyar sus programas mediante la selección de germoplasma asistida por marcadores moleculares y a los productores de papa les dará la seguridad de utilizar variedades tolerantes a la enfermedad.

\section{MATERIALES Y MÉTODOS}

Material genético y extracción de DNA. El trabajo se realizó durante 2003 y 2004 en la unidad de investigación en biología celular y molecular del Instituto Nacional de Investigaciones Forestales, Agrícolas y Pecuarias (INIFAP), ubicado en la Facultad de Ciencias Biológicas de la Universidad Autónoma de Nuevo León, San Nicolás de los Garza, Nuevo León, México. Se evaluaron 17 variedades comerciales y ocho líneas avanzadas de papa, procedentes del banco de germoplasma del INIFAP de México, ubicado en el estado de México y Nuevo León (Cuadro 1). Se utilizaron tres plantas por genotipo y se corrieron tres ensayos diferentes en forma simultánea para cada tipo de marcador. La extracción de DNA genómico se realizó utilizando la metodología descrita por Almeyda (1999).

Evaluación de la severidad de la coloración parda en los tubérculos. Fue evaluada la severidad de la enfermedad en seis localidades de los estados de México y Tlaxcala durante siete años, con base en la aparición del color pardo en el tubérculo, luego de haber observado el síntoma de punta morada en la planta. Se detectaron fitoplasmas mediante el método de PCR. Los tubérculos de cada muestra fueron cortados en forma transversal y se tomaron lecturas de la aparición del color pardo en el tubérculo con base en la escala: $1=\sin$ coloración parda; $2=$ muy leve; $3=$ leve; $4=$ leve moderado; $5=$ moderado $; 6=$ moderado fuerte, y $7=$ fuerte. Posteriormente, los tubérculos se almacenaron y se observaron para determinar su tipo de brotación.

Análisis RAPD. Mediante esta técnica, se evaluaron tres iniciadores (uno de forma individual y dos combinados) con diferentes proporciones de guanina-citosina (50 y $70 \%$ G-C respectivamente) como nucleótidos selectivos (Cuadro 2). Las reacciones de
Cuadro 1. Genealogía del germoplasma utilizado para identificar marcadores moleculares asociados a la resistencia a punta morada. San Nicolás de los Garza, Nuevo León, México 2003-2004.

\begin{tabular}{cll}
\hline Número & Genotipo & Genealogía \\
\hline 1 & $91-12-2$ & Ireri x F.L. \\
2 & $91-25-4$ & Ireri x F.L. \\
3 & $72-00-88$ & Desconocido \\
4 & Alpha & Paul Kruger x Preferent \\
5 & $91-9-3$ & Atlantic x 750489 \\
6 & Atlantic & Waseon x B5141-6 \\
7 & Gigant & Elvira x AM - 66-42 \\
8 & $91-10-1$ & Murca x Nook sack \\
9 & Montserrat & 7-AM-9 x57-DZ-23 \\
10 & Fiana & $4062-660$ x AM-66-42 \\
11 & Norteña & Atzimba x US-8 \\
12 & Zafiro & 575042 x 575042 \\
13 & $57-50-12$ & Desconocido \\
14 & Atzimba & US-133-3 x 52-AT-1 \\
15 & Malinche & 58-ER-1 x Loman \\
16 & Marciana & SACO X 57-DZ-23 \\
17 & Granola & 3333 60 X 267 04 \\
18 & Lady Rosetta & Cardinal x SVP VTn2 62 33 3 \\
19 & $4-11$ & Autofecundación P-14 \\
20 & Michoacán & Amarillo Puebla X 62 - HM - 5 \\
21 & Lupita & Desconocido \\
22 & 67-60-08 & Desconocido \\
23 & Rosita & 57 - AO - 10 X 52 AT - 1 \\
24 & Sancal & 750821 X 720054 \\
25 & Nau 6 & Desconocido \\
\hline & & \\
\hline
\end{tabular}

PCR se realizaron en un volumen final de $25 \mu \mathrm{l}$, se mezclaron 2,5 $\mu \mathrm{l}(1 \mathrm{X})$ de solución amortiguadora, 1,5 $\mu \mathrm{l}$ de $\mathrm{MgCl}_{2}(2 \mathrm{mM}), 2,0 \mu \mathrm{l}$ de dNTPs $(200 \mu \mathrm{M}), 2,0$ $\mu \mathrm{l}$ de cada iniciador $(0,5 \mu \mathrm{M}), 0,5 \mu \mathrm{l}$ de Taq polimerasa (2,5 unidades), $2 \mu \mathrm{l}$ de DNA (50 ng) y $12,5 \mu 1 \mathrm{de}$ agua MQ estéril. Cuando se utilizó la combinación de dos iniciadores se agregaron 2,0 $\mu \mathrm{l}(0,5 \mu \mathrm{M})$ de cada iniciador. Las condiciones de PCR fueron: a) $3 \mathrm{~min}$ a $94{ }^{\circ} \mathrm{C}$; b) 35 ciclos de 1 min a $94{ }^{\circ} \mathrm{C}$; 1 min a $36{ }^{\circ} \mathrm{C}$ y 1,5 min a $72{ }^{\circ} \mathrm{C}$ y una extensión final de 7 min a 72 ${ }^{\circ} \mathrm{C}$. Los productos amplificados se separaron en geles 
de poliacrilamida al $6 \%$ y se tiñeron con bromuro de etidio, para ser visualizados en fuente de luz ultravioleta para su análisis.

Análisis SSR. En la técnica de microsatélites se utilizaron tres pares de iniciadores, seleccionados con base en el número de genotipos que pueden diferenciar (Cuadro 2) Ashkenazi et al. (2000) y Ghislain et al. (2000), Las reacciones de PCR se realizaron en un volumen final de $25 \mu \mathrm{l}$; se mezclaron $2,5 \mu \mathrm{l}$ de solución amortiguadora (1X), $1,5 \mu \mathrm{l}$ de $\mathrm{MgCl}_{2}(2 \mathrm{mM})$, 2,0 $\mu \mathrm{l}$ de dNTPs $(200 \mu \mathrm{M}), 2,0 \mu \mathrm{l}$ de cada iniciador $(0,5 \mu \mathrm{M}), 0,5 \mu \mathrm{l}$ de Taq polimerasa (2,5 Unidades), 2 $\mu l$ de DNA (50 ng) y 12,5 $\mu \mathrm{l}$ de agua MQ estéril. Las condiciones de la PCR fueron: a) tres minutos a 94 ${ }^{\circ} \mathrm{C}$; b) 35 ciclos de un minuto a $94{ }^{\circ} \mathrm{C}$; dos minutos a $47^{\circ} \mathrm{C}$ y 1,5 minutos a $72{ }^{\circ} \mathrm{C}$; y una extensión final de cinco minuntos a $72{ }^{\circ} \mathrm{C}$. Los productos de amplificación se fraccionaron en geles de poliacrilamida al $6 \%$ y se tiñeron con nitrato de plata, Igloi (1983), para su posterior análisis. Ambas técnicas utilizando un termociclador MJ Research 100.

Análisis de datos. Todos los geles se analizaron y las bandas monomórficas y polimórficas se contabilizaron. Se asumió que bandas del mismo peso molecular en diferentes individuos eran similares. La presencia de una banda fue indicado por un uno (1) y la ausencia como cero (0) (Cuadro 3). Las relaciones genéticas entre genotipos se calcularon por el método de similaridad genética propuesto por Nei y Li (1979), usando el paquete de software S-Plus Versión 4.0. La matriz de distancias generada se utilizó para producir dendogramas por medio del método UPGMA (por su siglas en inglés, Unweighted Pair Group Method with Arithmetic Averages).

Para estimar la utilidad de los sistemas de marcadores en papa, se calcularon algunos parámetros propuestos por Powell et al. (1996), como el índice de

Cuadro 2. Iniciadores utilizados en la caracterización molecular de 25 genotipos de papa. San Nicolás de los Garza, Nuevo León, México. 2003-2004.

\begin{tabular}{|c|c|c|}
\hline \multirow{2}{*}{$\begin{array}{l}\text { Iniciador o par } \\
\text { de iniciadores }\end{array}$} & \multicolumn{2}{|c|}{ RAPD } \\
\hline & Iniciador Foward & Iniciador Reverse \\
\hline 2 & 5'-CGAACATGAG-3' & \\
\hline \multirow[t]{2}{*}{$23 / 30$} & 5'-GGCGATCACG-3' & $5^{\prime}$-CTCCTGCGAC-3' \\
\hline & \multicolumn{2}{|c|}{ SSR } \\
\hline M1F/M2R & 5'AATTCATGTTTGCGGTACGTC-'3 & 5’ATGCAGAAAGATGTCAAAATTGA-`3 \\
\hline M5F/M6R & 5'AACATTACAACACATTAGCA-'³ & 5’AACTTATCTGAAACTCTCGT-`3 \\
\hline M7F/M8R & 5'AATAGGTGTACTGACTCTCAATG-`3 & 5'TTGAAGTAAAAGTCCTAGTATGTG-`3 \\
\hline
\end{tabular}

Cuadro 3. Información proveniente del análisis de productos de PCR de la técnica RAPD en 25 genotipos de papa. San Nicolás de los Garza, Nuevo León, México. 2003-2004.

\begin{tabular}{|c|c|c|c|c|c|c|c|c|c|c|c|c|c|c|c|c|c|c|c|c|c|c|c|c|c|}
\hline \multirow{2}{*}{$\begin{array}{l}\text { Peso } \\
\text { Mol. }\end{array}$} & \multicolumn{25}{|c|}{ Genotipos } \\
\hline & 1 & 2 & 3 & 4 & 5 & 6 & 7 & 8 & 9 & 10 & 11 & 12 & 13 & 14 & 15 & 16 & 17 & 18 & 19 & 20 & 21 & 22 & 23 & 24 & 25 \\
\hline 4.000 & 1 & 0 & 0 & 1 & 0 & 1 & 1 & 1 & 0 & 1 & 0 & 0 & 0 & 0 & 1 & 0 & 0 & 0 & 0 & 0 & 0 & 0 & 0 & 0 & 0 \\
\hline 2.000 & 1 & 1 & 1 & 1 & 1 & 1 & 0 & 0 & 1 & 1 & 0 & 0 & 0 & 1 & 0 & 1 & 1 & 1 & 1 & 1 & 1 & 1 & 1 & 1 & 1 \\
\hline 1.800 & 0 & 0 & 0 & 0 & 0 & 0 & 0 & 0 & 0 & 0 & 0 & 0 & 0 & 0 & 0 & 1 & 1 & 1 & 1 & 1 & 1 & 1 & 1 & 1 & 1 \\
\hline 1.650 & 1 & 1 & 1 & 1 & 1 & 1 & 1 & 1 & 1 & 1 & 1 & 1 & 1 & 1 & 1 & 0 & 0 & 0 & 0 & 0 & 0 & 0 & 0 & 0 & 0 \\
\hline 1.500 & 1 & 1 & 1 & 1 & 1 & 1 & 1 & 0 & 1 & 1 & 1 & 0 & 1 & 1 & 0 & 0 & 0 & 0 & 0 & 0 & 0 & 0 & 0 & 0 & 0 \\
\hline 1.400 & 0 & 0 & 0 & 0 & 0 & 0 & 0 & 0 & 0 & 0 & 0 & 0 & 0 & 0 & 0 & 1 & 1 & 1 & 1 & 1 & 1 & 1 & 1 & 1 & 1 \\
\hline 1.200 & 0 & 0 & 0 & 0 & 0 & 0 & 0 & 0 & 0 & 0 & 0 & 0 & 0 & 0 & 0 & 1 & 1 & 1 & 0 & 0 & 1 & 1 & 0 & 0 & 1 \\
\hline 1.000 & 0 & 1 & 1 & 1 & 1 & 1 & 1 & 1 & 1 & 1 & 1 & 1 & 1 & 1 & 0 & 0 & 0 & 0 & 0 & 0 & 0 & 0 & 0 & 0 & 0 \\
\hline
\end{tabular}


diversidad mediante la ecuación: $\mathrm{ID}=1-\mathrm{p}_{\mathrm{i}}^{2}$, donde $\mathrm{p}_{\mathrm{i}}$ es la frecuencia del alelo $\mathrm{i}^{\mathrm{n}}$; en este caso, cada alelo individual se considera locus único y a su vez un fragmento de amplificación. La proporción múltiple efectiva (EMR), que es definida como producto de la fracción de loci polimórficos y el número total de loci polimórficos para un análisis por Oligonucleotidos RAPD y SSR. El índice de marcador (MI), cuya estimación es usada para evaluar la utilidad total de cada sistema de marcadores y se define como el producto de los promedios del índice de diversidad para los fragmentos polimórficos y el EMR para cada análisis. Se realizó el análisis utilizando los tres componentes principales para observar el grado de dispersión de los genotipos evaluados así como el comportamiento con base en las evaluaciones de campo y en los análisis moleculares.

\section{RESULTADOS}

Coloración parda de tubérculos. Los valores de severidad de la aparición de color pardo en los tubérculos (SPT) se muestran en la Figura 1 donde también se reportan el número de muestras utilizadas y los valores de diferentes estadísticos descriptivos para la evaluación de la SPT en 13 de los 25 genotipos de papa bajo estudio, estimados a partir de datos obtenidos de muestras de seis localidades de la mesa central de México.

Se distinguen tres patrones de comportamiento de la SPT: a) genotipos que presentan una distribución de frecuencias ubicadas en el rango de leve a leve-moderado de la escala de severidad, con una SPT media de

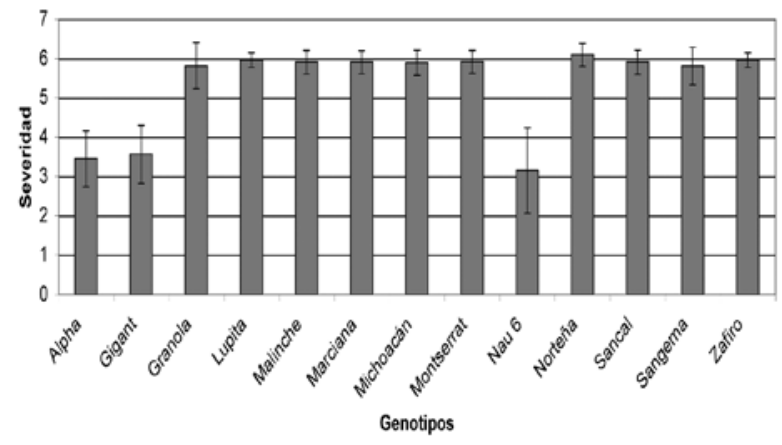

Figura 1. Pardeamiento de tubérculos en 13 variedades de papa, promedio de seis localidades de los estados de México y Tlaxcala durante 1995-2001.
3,15 a 3,56 se encuentran las variedades Alpha, Gigant y Nau 6; b) las variedades que presentan una SPT media de 5,81 a 5,90 que fueron Granola, Michoacán y Sangema; c) las variedades presentan una SPT media de 5,90 a 6,09 donde se incluyeron Lupita, Marciana, Malinche, Montserrat, Norteña, Sancal y Zafiro; este grupo se caracterizó por tener más del $90 \%$ de sus tubérculos con un nivel de coloración parda de moderado-fuerte a fuerte (seis a siete). El comportamiento en las distribuciones de frecuencias entre grupos fueron diferenciales, sólo el rango de valores y los extremos de severidad (mínimo y máximo) de los tubérculos del primer grupo ( 1 y 5 , respectivamente) fueron claramente distintos a los otros dos grupos, cuya distribución fue más estrecha y con valores extremos (4 y 7) más altos y cercanos entre sí.

Análisis RAPD. La técnica RAPD permitió diferenciar los 25 materiales de papa. Se observaron un total de 40 fragmentos (en promedio 20 fragmentos por iniciador), de los cuales 39 (97\%) fueron polimórficos y el $3 \%$ monomórficos (Cuadro 3). El tamaño de los fragmentos analizados estuvo en un ámbito de 250 a 4.000 pares de bases, no se consideraron los fragmentos de mayor y menor peso molecular, no se detectaron diferencias significativas en el número de bandas amplificadas entre iniciadores por el porcentaje de G-C.

Análisis SSR. En esta técnica se obtuvieron un total de 49 fragmentos diferentes (16,33 fragmentos en promedio), 48 (98\%) de ellos fueron polimórficos. El tamaño de los fragmentos observados estuvo en el ámbito de 100 a 850 pares de bases (datos no mostrados), aunque se observaron fragmentos de mayor y menor peso molecular; no se encontró diferencias significativas en número de fragmentos amplificados entre cada par de iniciadores.

Relaciones genéticas. El dendrograma conjunto de los dos sistemas de marcadores mostró diferencias en la forma de agrupamiento de los diferentes genotipos (Figura 2). En el primer caso se formaron dos grupos diferenciales el Grupo A que incluyó genotipos procedentes de Nuevo León y el grupo B formado con genotipos del Estado de México, donde cada grupo pertenece a la procedencia. El primero se subdividió a su vez en dos grupos homogéneos (A1, A2 y A3) donde se ubicaron las variedades Atlantic, Gigant y Alpha, además de las líneas avanzadas H91-9-3, H91-12-1, y H72-00-88, dentro de las cuales se encontraron las variedades con menor nivel de coloración parda de tubérculos (uno a tres en promedio). El subgrupo A2 fue heterogéneo, se 
formó con las variedades Montserrat, Norteña, Fiana, Atzimba y Zafiro, con las líneas H57-50-12, H91-10-1 y H91-25-4; asimismo en el subgrupo tres se formó con tres genotipos individuales que fueron H91-10-1, H9125-4 y la variedad Malinche, en este grupo el genotipo mas divergente fue la variedad Malinche (Figura 2), quienes mostraron lecturas de coloración parda intermedias (4 a 6). Por otra parte, el grupo B también se subdividió en dos subgrupos (B1 y B2); un grupo homogéneo formado con las variedades Sancal y Nau 6, que están cercanamente emparentadas y de ellas la segunda mostró tolerancia a coloración parda del tubérculo; el otro grupo muy heterogéneo, incluyó las variedades Marciana, Granola, Sangema, Lady Rosetta (con coloración parda tres a cuatro), Michoacán, Lupita y las líneas H67-60-08 y

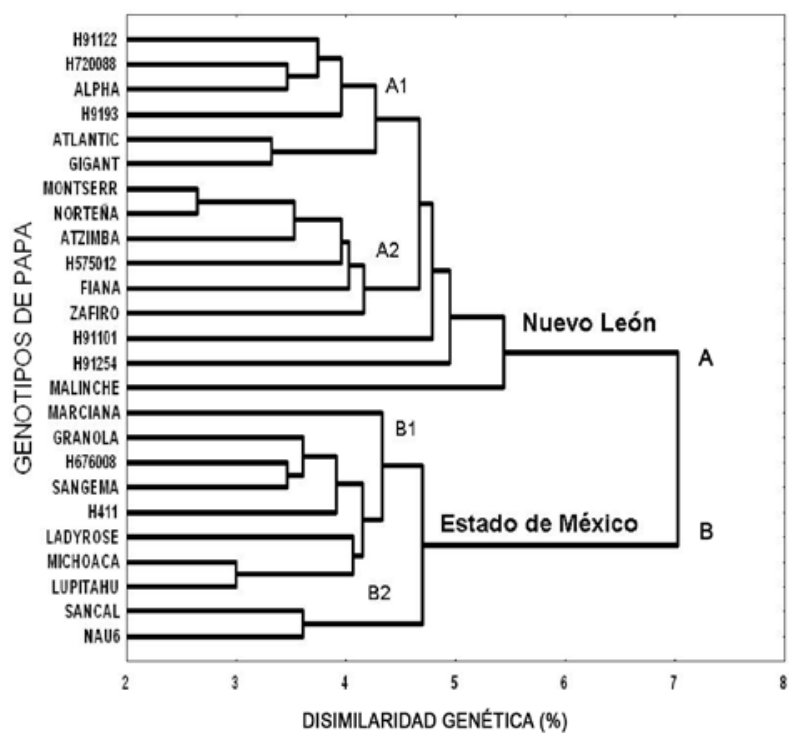

Figura 2. Relaciones genéticas entre 25 genotipos de papa resultado del análisis combinado RAPD - SSR y la similaridad genética de Nei y Li (1979), San Nicolás de los Garza, Nuevo León, México, 2003 2004.
H4-11, en este grupo se asociaron los genotipos con alto nivel de color pardo (entre grado 4 a 6 ).

Comparación de la utilidad de los marcadores. Con el fin de estimar la utilidad de cada sistema de marcador, se calcularon algunos parámetros reportados por Powell et al. (1996), como el índice de diversidad (ID), la proporción múltiple efectiva (EMR) y el índice de marcador (IM), (Cuadro 4). Los altos o bajos niveles de polimorfismo determinan el nivel del índice de diversidad genética presente en un grupo de individuos. En este caso se observó un nivel de diversidad en los genotipos evaluados tanto para RAPD como para SSR del 79,2\%.

En el análisis de componentes principales se observa claramente la dispersión de los genotipos evaluados, se formaron dos grupos, uno se subdividió y en un subgrupo se encuentran los materiales que mostraron altos niveles de daño de coloración parda del tubérculo que fueron Montserrat, Norteña, Atzimba, Fiana, Zafiro y Malinche con las líneas H57-50-12, H91-10-1 y H91-25-4; en el otro, los materiales que presentaron menor daño (Alpha, Atlantic, Gigant y las líneas avanzadas H91-12-2, H72-00-88 y H91-9-3). En el otro grupo las variedades Nau 6 y Sancal, se separaron del grupo de genotipos con alto nivel de daño, de los dos materiales indicados anteriormente Nau 6 fue la que presentó el más bajo nivel de daño (Figura 3).

\section{DISCUSIÓN}

En el presente trabajo se utilizaron tres clonas por variedades y se corrieron tres ensayos diferentes en forma simultánea obteniendo resultados idénticos, lo que indica una reproducibilidad de los resultados y que el manejo de las clonas fue el adecuado ya que no se detectó variación dentro de la misma variedad. Se pudieron reproducir los resultados con la técnica de RAPD contrario a lo citado por Demeke et al.

Cuadro 4. Productos obtenidos por sistema de marcador, productos polimórficos, Índice de Diversidad (ID), Proporción Múltiple Efectiva (EMR) e Índice de Marcador (IM) en promedio, San Nicolás de los Garza, Nuevo León, México, 2003-2004.

\begin{tabular}{ccccccccc}
\hline $\begin{array}{c}\text { Metodo- } \\
\text { logía }\end{array}$ & $\begin{array}{c}\text { Total de } \\
\text { análisis }\end{array}$ & $\begin{array}{c}\text { \# Total de } \\
\text { productos }\end{array}$ & $\begin{array}{c}\text { Total de prod. } \\
\text { polimórficos }\end{array}$ & $\begin{array}{c}\text { Promedio de } \\
\text { prod. por ensayo }\end{array}$ & $\begin{array}{c}\text { \% de prod. } \\
\text { Polimórficos }\end{array}$ & Media ID & EMR & IM \\
\hline RAPD & 2 & 40 & 39 & 20,0 & 97 & 0,7918 & 19,02 & 15,05 \\
SSR & 3 & 49 & 48 & 16,3 & 98 & 0,7918 & 1 & 0,82 \\
\hline
\end{tabular}




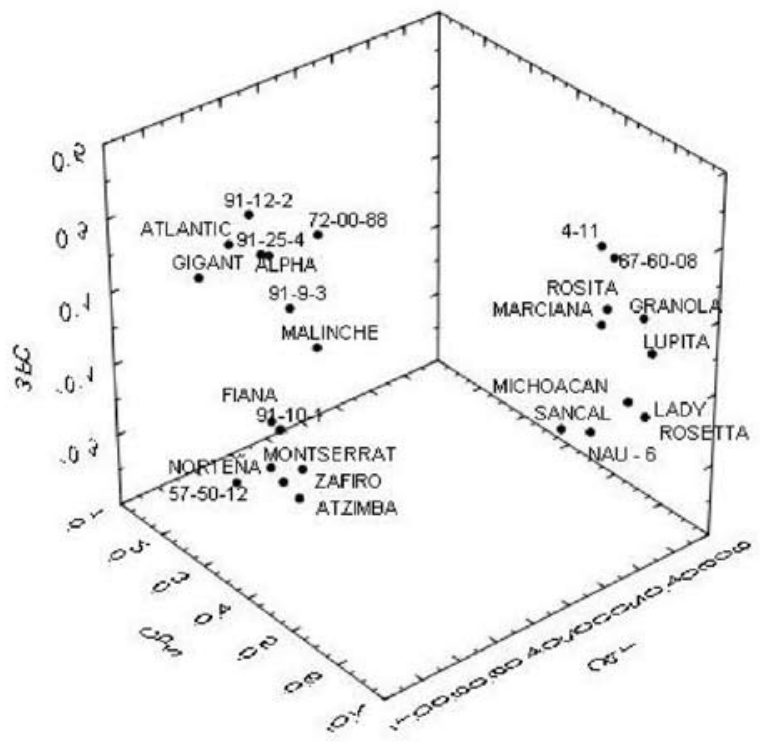

Figura 3. Dispersión de 25 genotipos de papa resultado del análisis de componentes principales de datos RAPD y SSR, San Nicolás de los Garza, Nuevo León, México, 2004-2004.

(1993) quienes mencionan que esta técnica es difícil de reproducir en diferentes laboratorios, y se corroboró lo reportado por Pecina et al. (2001). Además, los microsatélites tienen la ventaja de ser ampliamente reproducibles, de fácil uso, e implementación (Ghislain et al. 2000), ya que pueden detectar altos niveles de polimorfismo en $S$. tuberosum, por lo que pueden ser usados como herramienta para detectar las diferencias genéticas entre colectas relativamente cercanas Ashkenazi et al. (2000), Raker y Spooner (2002).

En el análisis de disimilaridad genética propuesto por Nei y Li (1979), se generó un dendograma donde pueden distinguirse los genotipos que mostraron tolerancia a la coloración parda del tubérculo, como es el caso de las variedades Gigant, Atlantic, Alpha y las líneas avanzadas H91-9-3, H91-12-2 y H72-00-88, esta última procedente de Argentina.

Las variedades Nau 6 y Sancal, formaron un grupo diferente del anterior, la primera mostró los valores más bajos de incidencia de coloración parda. Sancal mostró un valor alto, lo cual se puede explicar por el hecho de que posee algún gen que confiere cierta tolerancia aunque se desconocen sus progenitores alguno esta confiriendo esa tolerancia.
Asimismo el análisis agrupa los genotipos con valores altos de coloración parda en dos grupos (4-7), esta característica también se observa en el gráfico tridimensional del análisis de componentes principales realizado, por una parte están los genotipos con valores bajos de coloración parda y por otra parte aquellos genotipos con valores altos de coloración parda (Figura 3), Se observa que la variedad Malinche está en un punto intermedio entre genotipos, lo cual es un indicador de que este material puede tener cierta tolerancia a este daño. Los resultados obtenidos pueden ser de gran ayuda en los programas de mejoramiento genético con énfasis en la búsqueda de genotipos tolerantes al daño por fitoplasmas, asimismo con este estudio se corroboró la consistencia de los resultados obtenidos en campo con los resultados de los análisis moleculares.

El agrupamiento de unidades de distancias mínimas y promedios aritméticos propuesto por Nei y Li (1979), permitieron distinguir las diferencias genéticas existentes entre los 25 genotipos, lo que concuerda con los resultados obtenidos en otros trabajos Miller y Spooner (1999). También, el desarrollo de microsatélites en S. tuberosum analizada con el modelo propuesto por Nei y Li (1979) Figuras 2 y 3 soportan las diferencias genéticas de la mayoría de los genotipos, como ha sucedido en otros estudios Russell et al. (1997).

La diversidad genética evaluada a través de los análisis RAPD y SSR en papa mostraron un porcentaje muy similar (79\%), lo que puede ser un reflejo en la forma de variación observada por cada sistema de marcador, misma situación ha sido observada en soya por Powell et al. (1996).

En la Proporción Múltiple Efectiva (EMR) los marcadores RAPD, presentaron valores mayores que los SSR (9,4 y 1), lo cual es normal debido a que se asume que SSR únicamente revela un solo locus, mientras que en el caso de los RAPD se asumió que cada banda pertenece a un locus distinto. Si se considera que la papa es una especie tetraploide, se puede asumir que un locus o alelo puede existir en cuatro formas distintas, por lo tanto es contradictorio que en los análisis SSR se mencione que sólo se está amplificando un solo locus. Por lo tanto, el valor de 1 asignado en EMR para SSR incide en bajos valores de su índice de marcador (IM), aún cuando pudieran ser utilizadas algunas combinaciones de oligonucleotidos iniciadores que puedan revelar más de un locus, Milbourne et al. (1997). 


\section{CONCLUSIONES}

Se identificaron marcadores moleculares asociados con la resistencia a la punta morada en papa. Debido a que el número de iniciadores RAPD y SSR utilizados fueron nueve, es necesario realizar análisis con mayor cantidad de iniciadores. El mejoramiento genético asistido con las técnicas moleculares reducirá en tiempo la liberación de variedades resistentes a la enfermedad causada por fitoplasmas. Se pueden reproducir los resultados con RAPD en diferentes laboratorios por lo que se sugiere usar las condiciones descritas en este trabajo para estudios posteriores; y corroborar los resultados observados en campo, con base en los análisis moleculares, que permitieron agrupar los genotipos con menor índice de daño por coloración parda.

\section{LITERATURA CITADA}

Almeyda, LIH; Rubio, O; Cadena, HMA; Díaz, M; Zavala, TE; Rocha, PMA; Díaz, A. 1999. Implementación de técnicas moleculares para la detección del agente causal de la punta morada de la papa en plantas e insectos vectores. Proyecto de investigación, Laboratorio de Patología Molecular-Monterrey. INIFAP, Informe de Avances. 19 p.

Ashkenazi, V; Chani, E; Lavi, U; Levy, D; Hillel J; Veilleux, RE. 2000. Development of microsatellite markers in potato and their use in phylogenetic and fingerprinting analysis. Genome 44: 50-62.

Borth, WP; Hamasaki, RT; Ogata, D; Fukuda, SK; Hu, JS. 2002. First report of phytoplasmas infecting watercress in Hawaii. Plant Disease 86: 331.

Cárdenas, SE; Valdovinos, PG; Cadena, HM; Estañol, BE. 1992. Detección de organismos tipo micoplasmas en plantas de papa con los síntomas de "punta morada". Memorias del XXI Congreso Nacional de la Sociedad Mexicana de Fitopatología. Cuernavaca, Morelos, México. p. 62.

Demeke, T; Kawchuk, LM; Lynch, DE. 1993. Identification of potato cultivars and clonal variants by random amplified polymorphic DNA analysis. American Potato Journal 70: 561 - 570 .
Doi, Y; Teramaka, M; Yora, K; Asuyama, H. 1967. Mycoplasma or PLT group-like microorganisms found in the phloem elements of plants infected with mulberry dwarf, potato witches' broom, aster yellows, or Paulownia witches' broom. Annual Phytopathology. Society Japanese 33: 259-266.

Ghislain, M; Rodríguez, F; Villamón, F; Núñez, J; Waugh, R; Bonierbale, M. 2000. Establishment of microsatellite assays for potato genetic identification. CIP Program Report. 1999-2000. p. 167-174.

Igloi, GL. 1983. A silver stain for detection of a nanogram amounts of RNA following two-dimensional electrophoresis. Annual Biochemistry 134: 184-188.

Kochieva, EZ. 2000. Molecular markers of potato and tomato species and cultivars Genome. N.I. Vavilov. Institute of General Genetics. Moscow, Russia. p. 14-23.

Laviña, A; Battle, A. 2002. First report of stolbur Phytoplasma in avocado en Spain. Plant Disease 86: 692.

Lee, Ing-Ming; Dawn, E; Gundersen, R; Bertaccini, A. 1998. Phytoplasma: Ecología y diversidad genómica. Phytopthology 88: 1359-1366.

Leyva, LNE; Martínez-Soriano, JP. 2002. Diagnóstico diferencial de fitoplasmas en papa y su aplicación en la búsqueda de vectores. Memorias del Taller Internacional de Trabajo sobre la Punta Morada de la Papa y Paratrioza cockerelli. INIFAP y CONPAPA. Enero 17, 2002. Toluca, Edo. de México. p. 34-51.

Martínez, SJP; Leyva, LNE; Zavala, SME; Beres, M; LealKlevezas, DS. 1999. Detección molecular del agente causal de la "bola de hilo" de la papa en semillas infectadas y asintomáticas. Biotecnología Aplicada 16: 93 .

Milbourne, D; Meyer, R; Bradshaw, JE; Baird, E; Bonar, N; Provan, J; Powell, W; Waugh, R. 1997. Comparison of PCR-based marker systems for the analysis of genetics relationships in cultivated potato. Molecular breeding 3: 127-136.

Miller, LT; Spooner, DM. 1999. Collapse of species boundaries in the wild potato Solanum brevicaule complex 
(Solanaceae, S. sect. Petota): Molecular data. Plant System Evolution 214: 103-130.

Nei, M; Li, W. 1979. Mathematical model for studying genetic variation in terms of restriction endonucleases. Proceedings of the National Academy of Sciences of the United States of America 76: 5269-5273.

Powell, W; Morgante, M; Andre, C; Hanaffey, M; Vogel, J; Tingey, S; Rafalski, A. 1996a. The comparisons of RFLP, RAPD, AFLP and SSR (microsatellite) markers for germoplasm analysis. Molecular Breeding 2: 225-238.

Raker, MC; Spooner, DM. 2002. Chilean tetraploid cultivated potato, Solanum tuberosum, is distinct from the Andean populations: microsatellite data. Crop Science 42: 1451-1458.

Russell, RJ; Fuller, DJ; Macaulay, M; Hatz, BG; Jahoo, A; Powell, W; Waugh, R. 1997. Direct comparison of level of genetic variation among barley accessions detected by RFLP's, AFLP's, SSR and RAPD. Theoretical and Applied Genetics 95: 714-722.

Salazar, LF. 1998. Fitoplasmas un factor negativo para la producción de semilla de papa (en línea). In Info papa foro de discusión sobre investigación en papa en América Latina. CIP. Lima, Perú. Consultado: 20 julio 2003. Disponible en: http://www.condesan.org/eforos/infopapa/index.htm

Villalobos, W; Moreira, L; Rivera, C. 2002. First report of an aster yellows subgroup $16 \mathrm{Sr}$ I - B phytoplasma infecting chayote in Costa Rica. Plant Disease 86: 330.

Yu, YG; Saghai, MA; Buss, GR; Maughan, PJ; Tolin, SA. 1994. RFLP and microsatellite mapping of a gene for soybean mosaic virus resistance. Phytopathology 84: 60-64. 
